\title{
The Aspect Marker -Le in Early Child Mandarin*
}

\author{
Hsiang-Hua Chang \\ Oakland University
}

\begin{abstract}
Cross-linguistically, researchers have found a distributional bias of tense/aspect markers in child languages, namely, children initially use past or perfective morphology with telic predicates and use present or progressive morphology with atelic predicates. One attempt to explain this phenomenon is the Prototype Account, which argues that children acquire a linguistic category starting with the prototype of the category and later extend its application to less prototypical cases (Shirai \& Andersen 1995). Based on the English data, they argue that children do not distinguish between past/perfective and telicity, which is the prototype for category past and category perfective.
\end{abstract}

\footnotetext{
* I would like to express my deepest gratitude to my thesis advisor, Prof. Cristina Schmitt, for comments and discussions on an earlier version of this paper. I thank the three anonymous reviewers and the managing editor for comments. I am also grateful for the research participants and their family. Any remaining mistakes are solely mine.
}

Hsiang-Hua Chang

Department of Modern Languages and Literatures, Oakland University

Rochester, Michigan 48098, United States of America

Phone: 12483704248; Email: chang23@oakland.edu

Received August 31, 2012; Revised December 23, 2012; Accepted January 17, 2013. 
This study presents evidence from Mandarin data of two young children, which supports the distributional bias found in the older children in Li (1990), but opposes the Prototype Account given the fact that Mandarin-speaking children do not have a macro-category of past/perfective/telic marked by the perfective -le. The finding argues for (i) a separation between past and perfective/telic and a separation between perfective and telic in child Mandarin, (ii) the necessity to distinguish perfective -le from sentence final le, (iii) the legitimacy to treat Mandarin adjectives as stative verbs, and (iv) the importance to examine verbs appearing in their basic forms without aspect markers.

Keywords: Mandarin Chinese, language acquisition, aspect, spontaneous speech

\section{Introduction}

Aspect, which characterizes different ways of viewing the internal temporal constituency of a situation (Comrie 1976) has inspired many cross-linguistic studies in language acquisition. For children to acquire aspect, they need to grasp not only the meaning of verbs, but also the temporal properties of events given in many cases by a combination of tense and aspect morphology and properties of nominal expressions.

Studies of aspect recognize two kinds of aspect: lexical aspect and grammatical aspect. Lexical Aspect, Aktionsart, expresses the inherent temporal properties of the predicate. Telic predicates, which involve logical endpoints, can be found in accomplishment predicates such as build a house, or achievement predicates such as fall or die. Stative predicates such as love or know, and activity predicates such as run or walk are called atelic predicates because they exclude logical endpoints.

Grammatical Aspect marks temporal viewpoints of an event by utilizing linguistic devices, such as inflections. In English, for 
instance, past tense and have-past participle are in many cases used to indicate perfective aspect as in I wrote a letter and I have found my glasses. Present tense and be-progressive specify imperfective aspect as in he walks or he is walking.

The functions of both lexical aspect and grammatical tense/aspect have continually caught researchers' attention, and the interactions between the two have also motivated various studies (Shirai \& Andersen 1995, Li \& Bowerman 1998, Wagner 1998, Li \& Shirai 2000, Swift 2000, Weist 2002, to name a few). In language acquisition, a hypothesis called Aspect First involving the interaction between lexical aspect and grammatical tense/aspect has been attested cross-linguistically (see Wagner 1998, Bohnemeyer \& Swift 2004 for a review). Researchers have argued that children initially use tense and grammatical aspect morphology to indicate lexical aspect and only later start to use them appropriately, namely, children first use past tense and/or perfective morphology to mark telicity, and use present tense and/or imperfective morphology to mark atelicity (Wagner 1998: 86). The evidence consistent with Aspect First hypothesis that in child language past/perfective is connected with telicity and present/imperfective with atelicity implies that there may exist an early stage where children treat both past/perfective/telic and present/imperfective/atelic as combinations, or as what I will call 'macro-categories.' This implication serves as the basis of the Prototype account for the Aspect First hypothesis, which claims that children acquire a linguistic category starting with the prototype of the category, and later extend its application to less prototypical cases (Shirai \& Andersen 1995). In other words, children acquire the category past starting by attaching it with its prototypes, which possess the features, [+telic], [+punctual], and [+result], as achievement verbs do. Based on the data of three English-speaking children from age $1 ; 6$ to $2 ; 4$, Shirai \& Andersen argue that in the initial stage children do not distinguish between past/perfective and telic because when they produce past inflections, nearly $100 \%$ of them 
appear with achievement verbs.

Following the Prototype account, when children are acquiring Mandarin, a language without tense morphology, they will first use perfective markers to mark telicity and use imperfective markers to mark atelicity. This prediction is attested in Li's experimental studies with Mandarin-speaking children from age three to six (Li 1990, Li \& Bowerman 1998, Li \& Shirai 2000). A clear association is found between telic verbs and the so-called perfective -le (but see Sybesma 1999, Klein et al. 2000) and between atelic verbs and the imperfective aspect markers. However, because the distributional bias in these data becomes stronger with age, rather than weaker as predicted by the Aspect First hypothesis (and the Prototype account), Wagner (1998) raises doubts about whether child Mandarin supports the Aspect First hypothesis.

This study presents evidence from Mandarin natural speech data of two children from age $2 ; 0$ to $2 ; 6$ and $2 ; 9$ to $3 ; 3$, supporting the distributional bias found in the older children in Li's research. Contrary to Shirai \& Andersen's conclusion, I present evidence, based on the aspect marker -le, against the Prototype account, showing that children do not have a macro-category of past/perfective/telic marked by $-l e$. The finding argues for a separation between past and perfective/telic and for a separation between perfective and telic in child Mandarin.

In this article, I will first introduce the lexical aspect and grammatical aspect markers in Mandarin and their interactions. The acquisition order of these aspect markers will also be discussed. Next, based on the study of Shirai \& Andersen and Li \& Bowerman, I will present an overview of the English and Mandarin evidence consistent with the Aspect First hypothesis and the Prototype account for these facts. Third, I will discuss hypotheses associated with the Prototype account. Finally, I will present the speech data of two children to examine my hypotheses and predictions and argue for reexamining the Prototype assumptions regarding the acquisition of tense/aspect morphology 
in child language.

\section{Aspect in Mandarin}

\subsection{Lexical Aspect}

According to Smith (1997), lexical aspect, or situation aspect in Smith's terms, can be defined and exemplified as follows. (i) States are static and durative (e.g., know, love); (ii) activities are durative and atelic events (e.g., laugh); (iii) accomplishments are durative, telic events consisting of a process with successive stages and an outcome (e.g., build a house, learn Greek); (iv) achievements are telic, instantaneous events (e.g., win the race); (v) semelfactives are atelic, instantaneous events (e.g., tap, knock). The Mandarin examples of different lexical aspects are shown in (1a-e). ${ }^{1}$

(1) a. wo renshi ta.

I know he

'I know him.'

b. wo changchang xiao.

I often laugh

'I laugh often.'

c. wo gai-le yi-dong fangzi.

I build-LE one-CL house

'I built a house.'

1 Labels used in this paper: $\mathrm{CL}$-nominal classifier, SFP-sentence final particle, GEN-genitive marker, QM-question marker, RVC—resultative verb compounds, MLU-mean length of utterances 
12 The Aspect Marker -Le in Early Child Mandarin

d. wo ying-le yi-chang bisai.
I $\begin{aligned} & \text { win-LE } \\ & \text { 'I won a race.' }\end{aligned}$
e. wo yizhi
I continuously knock door
'I keep knocking (the) door.'

There is a sub-category of verbs in Mandarin called Resultative Verb Compounds (RVC) (Li \& Thompson 1981: 54-68). In the examples below, da-kai (hit-open) 'open' in (2a) is an RVC, and both $d a$ and kai can serve as a main verb on their own, as in (2b) and (2c), respectively. The two verbs $d a$ and kai become one verb in $\mathrm{RVC}$ construction and together they share one aspect marker -le and assign thematic roles to the subject and object.

(2) a. ta da-kai-le yi-shan chuanghu.

he hit-open-LE one-CL window

'He opened a window.'

b. ta changchang da ta meimei. he often beat his younger:sister

'He beats his younger sister (very) often.'

c. ta kai-le yi-ping jiu.

he open-LE one-CL wine

'He opened a bottle of wine.'

Consistent with Li \& Shirai's proposal (2000), I argue that RVCs are achievements, not accomplishments (Smith 1997). I found that within the temporal clause of de shihou 'when,' only RVCs and achievement verbs can take -le, as shown in (4c), (5c), and (6b). All types of verbs can appear in their root forms in the (a) cases below. After adding the aspect marker -le in (3b), (4b), 
and (5b), these sentences become unacceptable. One way to save (4b) and (5b) is to alter them into an RVC construction as in (4c) and $(5 \mathrm{c})$. This provides one strand of evidence to support the claim that RVCs are achievement verbs because only achievement verbs can take -le in this kind of temporal clauses.

(3)

$\begin{array}{lllll}\text { a. ni } & \text { ai } & \text { ta } & \text { de shihou, } \\ \text { you } & \text { love } & \text { her } & \text { when, } \\ \text { zenme } & \text { mei } & \text { xiang } & \text { name } & \text { duo? } \\ \text { why } & \text { not } & \text { think } & \text { so } & \text { much }\end{array}$

'When you loved her, why (you) didn't think so much?'

b. *ni ai-le ta de shihou ... you love-LE her when ... 'When you loved her...'

(4) a. ni kan ta de shihou, ta zai ku ma? (activity) you see her when, she ZAI cry QM? 'When you saw her, was she crying?'

b. *ni kan-le ta de shihou ... you see-LE her when ... 'When you saw her...'

c. ni kan-dao-le ta de shihou ... $(\mathrm{RVC})$ you see-reach-LE her when ... 'When you saw her...'

(5) a. ?ta gai yi-dong fangzi de shihou ... (accomplishment) he build one-CL house when ... 'When he builds one house . . .' 
b. *ta gai-le yi-dong fangzi de shihou ... he build-LE one-CL house when ... 'When he built one house ...'

c. ta gai-hao-le yi-dong fangzi de shihou ... (RVC) he build-finish-LE one-CL house when . . . 'When he finishes/ed building a house ...'

(6) a. ta si de shihou...

he die when...

(achievement)

'When he dies/died ...'

b. ta si-le de shihou ...

he die-LE when ...

'When he dies/died ...'

Adjectives in Mandarin form another controversial category that needs to be discussed. Because adjectives can function as the head of the main predicate in Mandarin, Li \& Thompson (1981) call them adjectival verbs. McCawley (1992) also argues that Mandarin does not have the category of adjectives based on two observations. First, 'degree and comparative expressions combine more directly with adjectives than with verbs.' Therefore, if hao 'good' in (7) is an adjective, the sentences in (8) should be grammatical (McCawley 1992: 233-234). The ungrammaticality of sentences in (8) makes it evident that hao ren 'good person' is a compound, not a phrasal unit, and hao 'good' is not an adjective because it cannot take degree modifiers.

(7) ta shi yi-ge hao ren.

he be one-CL good person

'He is a good person.' 
(8) a. *ta shi yi-ge hen hao ren. he be one-CL very good person 'He is a very good person.'

b. *ta shi yi-ge bu hao ren. he be one-CL not good person '*He is a not good person.'

c. *ta shi yi-ge bi ni hao ren. he be one-CL than you good person 'He is a better person than you.'

d. *ta shi wo de zui hao pengyou. he be I GEN most good friend 'He is my best friend.'

Second, if hao 'good' is an adjective, the structure of 'hao + noun phrase' should be productive. However, the acceptability of such a structure decreases as the length of the noun phrase increases, as shown in (9) (McCawley 1992: 235). McCawley claimed that if it is the phonology or morphology of these noun phrases that determines their acceptability, this argues that 'the rule licensing such combinations is one of word-formation rather than of syntax.' Thus, hao 'good' is not an adjective and hao jiu 'good liquor' is a compound rather than a phrasal noun.

(9) a. yi-bei hao jiu one-CL good liquor

'a glass of good liquor'

b. yi-bei hao pijiu one-CL good beer 'a glass of good beer' 
c. ?yi-bei hao putaojiu one-CL good grape-wine 'a glass of good grape wine'

d. ??yi-bei hao Shaoxing huangjiu one-CL good Shaoxing yellow-liquor 'a glass of good Shaoxing liquor'

In addition to the statements above, which argued that the so-called Mandarin adjectives do not behave as the universally defined adjectives, McCawley also asserted that Mandarin verbs are adjective-like because they can combine directly with degree and comparative expressions as exemplified in (10).

(10) a. wo hen xihuan ta.
I very like he
'I like him very much.'

b. wo bi ni xihuan ta.

I than you like he

'I like him more than you do.'

I assume McCawley's argument that Mandarin adjective-like words are verbs. In the next section, I will illustrate that Mandarin adjective-like verbs (henceforth 'adjectival verbs') behave as stative verbs.

\subsection{Grammatical and Lexical Aspect Interaction}

Mandarin has no markers for tense. Instead, the speakers use adverbial time phrases, such as yesterday or next year, to indicate time; however, time phrases are not required in grammatical sentences. Without tense morphology in Mandarin, aspect markers reasonably become the focus when studying how language encodes 
temporal relations. Although it is not conclusive how many aspect markers there are in Mandarin (Li \& Thompson 1981, Egerod 1994, Li \& Bowerman 1998), only four traditionally acknowledged aspect markers will be discussed in this section, namely, the imperfective zai, -zhe and the perfective -le and -guo. The focus of this study is on the co-occurring relations between aspect markers and verb types, i.e., grammatical and lexical aspect interaction.

\subsubsection{The Imperfective Markers zai and -zhe}

Zai is a progressive marker, and it occurs only with situations that include processes, as shown below.

(11) ta zai tiaowu.

he ZAI dance

(activity)

'He is dancing.'

(12) ta zai da dianhua.

he ZAI make telephone

(accomplishment)

'He is making a phone call.'

(13) wo zai qiao men.

(semelfactive)

I ZAI knock door

'I am knocking the door.'

In general, the progressive zai is incompatible with stative verbs, as in (14a), but it is possible to find contexts in which this construction is acceptable as in (14b). This is also true for adjectival verbs. In (15a), feng 'crazy' appearing with zai is unacceptable, except when the progressive reading is enforced in (15b). Besides stative verbs, achievements do not take zai, either, as in (16). 
(14) a. *ta zai ai ni.

he ZAI love you

(state)

'He is loving you.'

b. ni zai hen wo ma?

you ZAI hate I QM?

'Are you hating me?'

(15) a. *ta zai feng.

he ZAI crazy

(state) (adjectival verb)

'He is acting crazily.'

b. ta you zai feng.

he again ZAI crazy

'He is again acting crazily.'

(16) *ta zai ying qiusai.

he ZAI win ball-game

(achievement)

'He is winning the ball game.'

The other imperfective marker, $-z h e$, does not focus on progress as zai does. It provides a stative view of situations (Yang 1995: 128). While one may find a sentence with a stative verb and -zhe seemingly acceptable as in (17a), Yang argues that -zhe usually does not appear with stative verbs because states are stative in nature and adding a stative marker -zhe will be redundant. But it is acceptable to use -zhe with states if certain emphasis is intended as in (17b). The statement also sustains when an adjectival verb is used, as in (18).

(17) a. ?Lili ai-zhe ta. Lili love-ZHE he

'Lili is loving him.' 
b. Lili sheng ai-zhe ta.

Lili deeply love-ZHE he

'Lili is deeply loving him.'

(18) a. ?mama mang-zhe.

(state) (adjectival verb)

Mom busy-ZHE

'Mom is busy.'

b. mama mang-zhe gongzuo.

Mom busy-ZHE work

'Mom is busy working.'

The imperfective marker $-z$ he can occur with semelfactives to get a repetitive reading as in (19) and work with activity verbs as in (20a) to get a durative interpretation. For the other situation types, accomplishments and achievements cannot appear with -zhe, as shown in (20b) and (21) because they emphasize the outcomes or the process of the event and thus are not compatible with -zhe, which 'presents a continuous and stable situation without regard to endpoints' (Smith 1997).

(19) ta qiao-zhe men han jiuming. (semelfactive)

he knock-ZHE door yell help

"While knocking the door, he yelled "help.",

(20) Examples revised from Yang (1995: 132)

a. ta ku-zhe gei mama xie yi-feng xin. (activity) he cry-ZHE to mother write one-CL letter 'While crying, he wrote a letter to Mom.'

b. *ta xie-zhe yi-feng xin gei mama ku. (accomplishment) he write-ZHE one-CL letter to mother cry 'While writing a letter to Mom, he cried.' 
(21) *ta yin-zhe qiusai.

(achievement)

he win-ZHE ball-game

'*He is winning the ball game.'

\subsubsection{The Perfective Markers -le and -guo}

It is widely accepted that -le and -guo are perfective markers in Mandarin. The major difference between -le and -guo is that the final state of -guo no longer obtains (Smith 1997). Take (22a) and (22b) for instance, they are identical except for the perfective markers. In (22a), Zhangsan may or may not be in New York at the speech time, while the only reading for $(22 b)$ is that Zhangsan is no longer there. For this reason, $-g u o$ is usually called the experiential marker.
a. Zhangsan qu-le New York.
Zhangsan go-LE New York
'Zhangsan went to New York.'
b. Zhangsan qu-guo New York.
Zhangsan go-GUO New York
'Zhangsan has been to New York.'

The perfective marker - $l e$ has been a problematic issue in Mandarin syntax and semantics because there appear to be two les: verb-le and the sentence final le. Considering two similar sentences in (23) and (24), it is likely that people may misunderstand the two les as possessing the same meaning as shown in their English translation.

(23) wo mai-le na-ben shu.

I buy-LE that-CL book

'I bought that book.' 
(24) wo mai na-ben shu le.
I buy that-CL book
'I have bought that book.'

No wonder that some researchers, such as Li (1990), do not distinguish verb-le from sentence le. Yet some researchers, Li \& Thompson (1981) and Sybesma (1999) among others, argue that verb-le and sentence $l e$ are not instances of the same morpheme. Viewing from its position in a sentence, we can define -le as a verbal suffix (verb-le) in (23) or as a sentence final particle (sentence le) in (24). Verb-le always follows a verb while sentence le may be adjacent to almost any type of words, including verbs. For instance, the sentence final le is next to a noun in (24). The two les have different roles in (23) and (24), although these sentences have exactly the same elements, except the position of le. As pointed out in Sybesma, verb-le focuses on the completion of the event as illustrated in (23), which means that the buying event is finished. Sentence le, also called 'currently relevant state' in Li \& Thompson's monograph, on the other hand, implies that the state expressed in the sentence did not hold in the past, as in (24), which means 'I did not purchase that book before, now I got it.' Accordingly, we can understand how the two les in (25) function differently: the verb-le indicates the completion of the activity while the sentence le specifies the new state that 'now I have bought that book.'

(25) wo mai-le nei-ben shu le.
I buy-LE that-CL book SFP
'I have bought that book (now).'

However, if a sentence final le occurs after a verb, as in (26), the problem arises whether this le is a verb-le, a sentence final particle, or the combination of both. 
(26) wo mai-le.

I buy-LE/SFP

'I bought (it).'

'I am going to buy (it) (now).'

$\mathrm{Lu}$ (1975) argues that the major difference between verb-le and sentence le is that sentence le always gives us the implication of the change of states, i.e., if the sentence le appears in an affirmative sentence, it implies that the situation has changed from the negative state to the positive state. For instance, sentence (25) implies that 'I did not buy that book before,' and the state has changed from 'did not buy that book' to 'bought that book.' On the contrary, Verb-le does not provide this kind of implication but emphasizes on the happening of the event. Accordingly, le in sentence (26) is perfective -le if the event of buying is focused and it can be interpreted as 'I bought it.' In the reading of 'I am going to buy it now,' as one may utter to a salesman after bargaining, le functions as the sentence le stressing the change of state or a currently relevant state. Also, Li \& Thompson (1981) argue that in a case where the sentence has the perfective meaning that is currently relevant, $l e$ is the combination of -le le and because -le le never occurs phonologically, we hear only one le. If their proposal sustains, le in (26) can also be interpreted as a combination of -le le because the event has perfective meaning-it is completed - and the event is currently relevant because the subject possesses the book now. So far, we may understand why previous researchers, such as Erbaugh $(1985,1992)$ and $\mathrm{Li} \&$ Bowerman (1998), did not try to distinguish verb-le from sentence le in their data because a sentence final le can be interpreted in different ways.

Fortunately, there is a way to differentiate verb-le from sentence le-the use of the negation morphology bu 'not' and mei(you) 'not-(have).' (You in mei(you) can be omitted.) Comrie (1976: 82) has noted that $b u$ 'not' negates sentence final le, while mei(you) 
'not-(have)' negates verb-le. Meiyou and verb-le cannot co-occur. Therefore, to negate a verb-le sentence as (23) (repeated below as (27a)), one should add meiyou and drop verb-le as in (27b). The appearance of meiyou and verb-le together will make a sentence ungrammatical as in $(27 \mathrm{c})$.
a. wo mai-le na-ben shu.
I buy-LE that-CL book
'I bought that book.'

b. wo meiyou mai na-ben shu.

I not-have buy that-CL book

'I did not buy that book.'
c. *wo meiyou mai-le na-ben shu. I not-have buy-LE that-CL book 'I did not buy that book.'

In contrast, the sentence final le in (28a) is secure when bu 'not' is inserted to form a negation sentence as in (28b) - bu and sentence le can co-occur.
a. wo mai na-ben shu le.
I buy that-CL book SFP
'I have bought that book.'
b. wo bu mai na-ben shu le. I not buy that-CL book SFP 'I am not going to buy that book.'

Being different from the perfective marker in some languages, which can co-occur with all situation types, -le is not acceptable with the situation types of states, activities, and semelfactivesbecause they are atelic or unbounded. In (29a), the stative verb $a i$ 
'love' is acceptable without any aspect markers. When the stative verb is used with the perfective marker -le, the sentence (29b) becomes unacceptable, unless endpoints are provided, as in $(29 \mathrm{c})$ where the adverbial phrase san-ge xueqi 'three-CL semester' offers an endpoint and makes the sentence a bounded event.
a. Lili ai ta.
Lili love he
'Lili loves him.'
b. *Lili ai-le ta.
Lili love-LE he
'Lili loved him.'

c. Lili ai-le ta san-ge xueqi.

Lili love-LE he three-CL semester

'Lili loved/has loved him for three semesters.'

The adjectival verb, feng 'crazy' in (30a), can also be used in a grammatical sentence without any aspect markers. However, in (30b), the adjectival verb can co-occur with -le, unlike the stative sentence in (29b). This appears to contradict what I just said. Yet, recall that when a verb-le is also sentence final, as in (30b), the meaning of -le will be ambiguous. Fortunately, the existence of a temporal adverbial phrase, such as yi-ge xingqi 'one week' in (30c), can make clear that adjectival verbs are verbs because they can appear with an unambiguous verbal suffix -le, similar to the case of (29c).

a. Lili hen feng.

(state) (adjectival verb)

Lili very crazy

'Lili is very crazy.' 
b. Lili feng-le.

Lili feng-LE/SFP

'Lili has been crazy.'

c. Lili feng-le yi-ge xingqi.

Lili crazy-LE one-CL week

'Lili has/had been crazy for a week.'

After making clear that feng 'crazy' functions as a verb, we are still puzzled by the acceptability of -le occurring with a stative verb in (30b), which contradicts the observation found in (29b) that stative verbs cannot appear with -le. Some other examples, such as (31) and (32), also indicate the acceptability of stative verbs with the perfective -le.

(31) ta you-le qian jiu wang-le lao pengyou. he have-LE money then forget-LE old friend 'As soon as he had money he forgot his old friends.'

(32) ta-de yanjing hong-le yi-ge xingqi hai mei hao. he-GEN eye red-LE one-CL week still not good 'His eyes have been red for a week and haven't recovered.'

For sentences (30b-c), (31), and (32), one possible interpretation is that the situations, crazy, have money, and red eyes, still sustain in the speech time. As Comrie (1976: 19-20) observes, the perfective marker -le specifies the ingressive viewpoint of the situation in these sentences:

In many languages that have a distinction between perfective and imperfective forms, the perfective forms of some verbs, in particular of some stative verbs, can in fact be used to indicate the beginning of a situation (ingressive reading) ... In Mandarin . . . both adjectives 
and verbs, that normally refer to a state can have ingressive meaning in the Perfective.

In short, perfective -le usually does not co-occur with stative verbs, such as ai 'love,' but it can appear with some specific stative verbs, like you 'have' or hong 'red' to mark the inception of the state.

Activity verbs, which are unbounded and atelic, cannot be used with -le, either, as in (33a). Sentence (33a) may be acceptable if le is a sentence final particle and the whole sentence means 'he escaped,' but this sentence is unacceptable with the intended meaning. After adding a bare nominal argument, as in $(33 \mathrm{~b})$, the sentence is still problematic and sounds like an incomplete sentence. The appearance of a nominal with a classifier can provide an endpoint in (33c), and thus makes the sentence grammatical.

a. \#ta pao-le.

he run-LE

(activity)

'He ran.'

b. ?ta pao-le malasong.

he run-LE marathon

'He ran marathon.'

c. ta pao-le yi-chang malasong.

he run-LE one-CL marathon

'He ran a marathon.'

Semelfactives are atelic, but they can be interpreted as bounded or unbounded. This explains why (34a), in which a semelfactive verb occurs with -le, is marginally acceptable because the situation can be either bounded or unbounded. Semelfactives need an extra delimiting mechanism, such as yi-ge xiawu 'one afternoon,' a 
quantifier phrase in (34b), to provide endpoints and make the sentence grammatical.

(34) a. ?deng shan-le.

(semelfactive)

light flash-LE

'The light flashed.' (revised from Yang 1995: 118)

b. deng shan-le yi-ge xiawu.

light flash-LE one-CL afternoon

'The light flashed for an afternoon.'

Based on the interactions between -le and different verb types (lexical aspect), endpoints are expressed usually by the verb itself (e.g., die, win) or the arguments of the verb (e.g., build a house). In Mandarin, -le is incompatible with stative, activity, and semelfactive verbs, but after adding a quantifier phrase, which offers endpoints to the situation, the ungrammatical sentences become acceptable, as shown in (29c), (33c), and (34b).

About the other perfective marker -guo, it can specify termination and thus is compatible with all situation types, as illustrated in the following examples.

a. wo ai-guo.

I love-GUO

'I have loved.'

(state)

b. wo kuaile-guo.

I happy-GUO

'I have been happy.'

c. wo xiao-guo.

(activity)

I laugh-GUO

'I have laughed.'

(state) (adjectival verb) 
d. wo gai-guo yi-dong fangzi. (accomplishment) I build-GUO one-CL house 'I have built a house.'

e. wo ying-guo.

(achievement)

I win-GUO

'I have won (before).'

f. wo qiao-guo men.

(semelfactive)

I knock-GUO door

'I have knocked the door.'

The suffix -guo emphasizes that the subject of the sentence has the experience of a specific event; thus, -guo is also called the experiential marker. For this reason, sentences (35a-e) can be best described as that the subject has had the experience of 'love, being happy, laughing, building a house, and winning,' and the event of 'knocking the door' in (35f) has been performed at least once. -Guo emphasizes the termination of the event and experience of the subject, but -le does not.

To sum up, the perfective -le gives us an external viewpoint of a situation, and this clearly contrasts with the imperfective marker $z a i$, which provides an internal view of the event. Because this contrast between perfective and imperfective markers is found not only in Mandarin but also in other languages, it is plausible to compare the grammatical and lexical aspect interaction in Mandarin with that in other languages, despite the fact that the aspectual system in different languages has different properties. Among the specific properties of -le is the fact that it can appear with telic verbs (accomplishment or achievement), but cannot appear with atelic verbs (stative, adjectival, or semelfative), unless some mechanism such as a quantifier phrase is used to provide a boundary to the situation denoted by atelic verbs.

Furthermore, there are two different les in Mandarin: 
perfective-le, which is a verbal suffix, and sentence final particle le, which appears at the end of a sentence and may follow any kind of phrases. In many cases, it is difficult to identify whether a sentence final -le is a perfective -le or a sentence le. But as mentioned earlier, negation is a way to distinguish between the two, and I will elaborate more on this point later.

\subsection{The Acquisition Order of Mandarin Grammatical Aspect}

Based on the data of four two year-olds, Erbaugh (1992) found that the acquisition sequence of the four aspect markers in Mandarin is the following: (i) -le (before 2;4), (ii) zai (around 3;0), (iii) -zhe, and (iv) -guo. She (1992: 425) claims that young children first master whichever time/aspect system their language makes central. Thus, young English speakers contrast past tense to progressive/simple present, young Spanish speakers contrast perfective with imperfective, and young Mandarin speakers should master perfective. In her study, children produced up to 2,300 les (because many were ambiguous between the perfective -le and the sentence le, she does not separate the two les). This sharply contrasts with 108 imperfective zais, 50 -zhes, and 34 experiential -guos. She notices that children use -le selectively. Children understand that -le typically co-occurs with past: $85 \%$ of $-l e$ refer to the past.

Generally, the child is the agent of an action in the immediate past. $73 \%$ of the early -le describe the child's own actions. In contrast, $50 \%$ of their imperfectives zai and -zhe describe someone other than the child. All the progressive zais are correctly formed with activity verbs. Children never use zai incorrectly with a stative verb. After about two and half years old, children start to use the other perfective marker, -guo, once in a while. In summary, Erbaugh's study found that -le is the first acquired aspect marker and it is used more predominantly than the other aspect markers. Also, it seems that -le and past tend to appear 
together.

\section{The Distributional Bias of Tense/Aspect and the Prototype Account}

In various child languages (e.g., English, French, Polish, Greek, Japanese, and Mandarin), researchers have discovered a strong relation between specific grammatical aspect and lexical aspect (see Wagner 1998, Bohnemeyer \& Swift 2004 for a review). These observations have motivated what has been called the Aspect First hypothesis:

Children initially use tense and grammatical aspect morphology to mark lexical aspect. In particular, children initially use present tense and/or imperfective morphology to mark atelicity and use past tense and/or perfective morphology to mark telicity (Wagner 1998: 86).

One of the accounts trying to explain the Aspect First phenomena is called the Prototype account (Shirai \& Andersen 1995). The Prototype account assumes a graded category membership and proposes that a category has its best exemplar(s), the prototype(s), and peripheral members. It differs from the classical theory of categorization, which assumes an all-or-nothing membership based on critical features. In language acquisition, the Prototype account predicts that children acquire a linguistic category starting with the prototype of the category, and later extend its application to less prototypical cases. Following this hypothesis, children acquire past/perfective morphology by first attaching it to its prototypes, achievement verbs, and later to other type of verbs, the less prototypical cases. In the same way, children acquire present/imperfective morphology by using it with 
activity verbs and later with other types of verbs. The following studies in English and Mandarin present evidence in accordance with the Prototype account.

\subsection{English}

Shirai \& Andersen (1995) used the data of three English-speaking children, i.e., Adam (2;3-4;10), Eve $(1 ; 6-2 ; 3)$, and Naomi $(1 ; 6-4 ; 9)$, from Child Language Data Exchange System (CHILDES), and coded the verbs into four types: state, activity, accomplishment, and achievement. They argue that the important factors involved in tense-aspect acquisition are the inherent lexical aspect of verbs, mothers' input and children's concepts of the prototypes of tense/aspect morphology. They found that children start using past inflections predominantly with achievement verbs and progressive inflections with activity verbs; and the same distributional bias is found in the speech of the mothers addressing to children.

In the speech data of the three mothers, past inflections are used more frequently $(58-64 \%)$ with achievement verbs and progressive inflections (53-61\%) with activity verbs. The acquisition patterns for past and progressive morphology among these three children in the initial stage also present a similar distribution: they primarily associate past marking with achievement verbs (94-100\%), and progressive inflection with activity verbs (58-75\%). Although these children also use progressive inflection with achievement verbs to a considerable extent (24-32\%), Shirai \& Andersen account for this fact by stating that progressive morphology was acquired earlier than past tense, i.e., before the stage they examined. Thus, the progressive inflection was used with all types of verbs while the past tense was mainly used with achievements. In general, the data of mothers and children both support the distributional bias of tense/aspect morphology found cross-linguistically and are in accord with the prediction of Aspect First hypothesis. Accordingly, Shirai \& Andersen claim that this distributional bias found in child 
language can be explained by the effect of the 'motherese.'

At the first stage of acquisition, these English-speaking children's almost exclusive use (94-100\%) of the past inflection with achievement verbs provides evidence for the argument that initially children do not distinguish between past/perfective and telic, i.e., when they produce past morphology, almost all of them appear with the telic verbs. And this inability of young children to distinguish between past, perfective, and telic supports the Prototype account that children acquire past morphology by first associating it with its prototype, the achievement verbs, and later with the other peripheral members, i.e., accomplishment, activity, and stative verbs.

\subsection{Mandarin}

The Aspect First hypothesis is also justified in Mandarin according to the experimental study of Li \& Bowerman (1998), which illustrates the importance of telicity in lexical and grammatical aspect interaction. They designed three experiments to test children aged from $2 ; 9$ to $6 ; 4$ on their understanding of the aspect markers by using verbs with six different categories: states, activities, accomplishments, achievements, semelfactives, and mixed telic-stative (e.g., wear).

The results of the comprehension and imitation task are consistent. Children of all ages comprehend the perfective -le better with telic verbs (resultative, achievement, and accomplishment verbs) than with atelic verbs (activity and semelfactive verbs), and they comprehend the progressive marker zai better with atelic verbs than with telic ones. For stative verbs, children understand the imperfective marker -zhe better than -le, while the mixed telic-statives, which depend on the aspect marker to indicate a telic action or a state, are understood well with both -zhe and -le. In the production task, children used -le $(92-100 \%$ in different age groups) and almost no zai $(0 \%$ to $8 \%)$ with achievement verbs and 
what they called locative accomplishment verbs, such as $q u$ xuexiao 'go to school.'

This research is consistent with the Aspect First hypothesis that children use imperfective markers, zai and -zhe, with atelic verbs to mark atelicity and use the perfective marker -le with telic verbs to specify telicity. To explain this phenomenon, Li \& Bowerman first comment that "the prototype hypothesis appears promising for explaining the acquisition of tense and aspect, while how a prototype is formed and modified has not been clear" (1998: 341). They emphasize the role of input in this distributional bias and suggest that the connectionist approach (Rumelhart \& McClelland 1986, Li \& MacWhinney1996) may be able to solve the problem of prototype forming because this model focuses on "children's ability to detect patterns in the linguistic input, possibly through the formation of prototypes by connectionist networks" (ibid.: 343).

\subsection{The Prototype Account}

To account for the distributional bias of Aspect First hypothesis, Shirai \& Andersen (1995) argue that what English-speaking children do is attaching the past inflection to the prototype of the category past, i.e., [+telic], [+punctual], [+result]. For example, the three children first marked past tense mainly on verbs such as broke or fell, which possess all features of the prototype. Because the prototypes of past tense and perfective aspect are very similar, it appears that children use past tense to encode perfective aspect or the inherent lexical aspect of telicity/punctuality. This is where the macro-category of past/perfective/telic occurs.

They claim that it is difficult to determine whether children use past morphology to encode past tense or perfective aspect. They refer to Dahl's statement (1985: 78) that "the prototypical perfective refers to a single punctual event occurred in the past with a clear result or end state." This assertion not only makes the prototype of category past and that of category perfective very 
'similar' as Shirai \& Andersen stated, but also makes them almost identical. The Prototype account explains that because of this near identicalness of prototype past and prototype perfective, past morphology appears to mark perfective aspect or lexical aspect of telicity. In other words, early past morphology encodes under-extended past tenses by attaching only to prototypical past and encodes lexical aspect features such as completive, perfective, punctual, telic, and so on. In short, children may initially restrict their use of tense/aspect inflections to the prototype of the category-recall that in the earliest stage, near $100 \%$ of the past -ed produced by their children appear with telic verbs - and then gradually extend the category boundary, and eventually acquire the adult norm.

The advantage of the Prototype account is that it provides logic for the initial state in child language, i.e., the distributional bias of aspect markers, and it can account for the developmental change. Its disadvantage is that it goes against the strong Continuity hypothesis, which proposes that child's intermediate grammar must be subsets of the adult grammar (Pinker 1984, Cairns 1996). Also, it assumes the values of aspect markers without scrutiny. For instance, for Mandarin data to support the Prototype account, it assumes that children know the meaning of -le as perfective, but this seems circular because if children knew the meaning of -le, they would use it as the way adults do.

\section{A Study of $-L e$ in Child Mandarin}

\subsection{Hypotheses and Predictions}

The hypothesis examined in this study is the Prototype account of Shirai \& Andersen (1995). In the spirit of the Prototype account, past/perfective/telic would appear as a macro-category 
marked by the past or perfective morphology in child language, which is attested in their study of English. The main research question of this study is whether Mandarin-speaking children have this macro-category of past/perfective/telic. If the answer is positive, Mandarin-speaking children may treat -le as a marker of past/perfective/telic. This predicts that -le will show up with telic verbs mainly in past contexts.

If children do not use -le as a grammatical aspect marker, but as a lexical aspect marker to mark the telicity of the verbs as the Aspect First hypothesis predicts, then regardless of the time reference, every time -le appears, a telic verb should also appear. In other words, -le should show up predominantly with telic verbs in both past and non-past contexts. If this proves to be true, then it will argue for a combination of perfective/telic, and against a mixture of past/perfective/telic in child language as the Prototype account predicts.

Lastly, if children possess the adult-like knowledge and know that past, perfectivity, and telicity are distinct categories, evidence is expected to support a separation between past, perfectivity, and telicity. A further question concerns the fact that there are two les in adult Mandarin, which are syntactically and arguably semantically distinct from each other. Do children use the two les similarly or differently? If children use the two les differently as adults do, then it will be clear that Mandarin evidence does not support the Prototype account for the acquisition of aspect markers, which predicts that Mandarin-speaking children predominantly use -le as a marker for the macro-category, past/perfective/telic.

\subsection{Methodology}

Longitudinal spontaneous speech data were collected for this study based on the following advantages. In spontaneous speech studies, children are recorded in settings, such as home or neighborhood playground, where they feel most comfortable to 
talk freely (Demuth 1996). Natural speech data is least likely to be influenced by inappropriate experimental task demands or the required repeated measures of the similar test, which affect children's performance. These are particularly advantageous when investigating the early stages of acquisition in young children (Stromswold 1996).

Given that it is relatively impractical to study one child for a very long period of time, it is helpful to collect data from children of overlapping ages. This strategy is especially useful when studying a topic as the current one where little acquisition work has been done (Demuth 1996). Two native Mandarin-speaking children were selected for this study. Nana's speech was recorded for two hours every month from age $2 ; 0$ to $2 ; 6$ (MLU: 1.73 to 3.18, 3257 utterances) and Didi's from age 2;9 to 3;3 (MLU: 2.34 to $3.57,4274$ utterances). The language production of both children fell in the period when the MLU is between 1.75 and 4 morphemes, which is arguably the morpho-syntactically interesting period (Demuth 1996: 4).

Regarding coding, for research that focuses on lexical and morpho-syntactic rather than phonological or phonetic issues, usually a broad phonemic (as opposed to narrow phonetic) transcription is used. For instance, Brown (1973) used the orthographic conventions of English for transcription. I used Pinyin, the official Chinese Romanization system used in China, to transcribe the data in the format of the Codes for the Human Analysis of Transcripts (CHAT) used by the CHILDES (MacWhinney 2000).

In this study, MLU is counted in terms of morphemes, rather than words or Chinese characters. I followed the commonly accepted notion that a morpheme is 'the smallest meaningful linguistic unit' (Cairns 1996) while at the same time I utilized particular coding methods to better match the current research focus. For instance, instead of assuming that children possess adult's knowledge of morphology, I took a more conservative way 
and followed the suggestion from CHAT Manual (p. 52, 161) (included in MacWhinney 2000) to treat some compounds, such as bathing-suit, High-street, or Santa-Claus, as one morpheme. As for RVCs, because the two elements of an RVC, e.g., po 'break' and diao 'drop' in po-diao (break-drop) 'break-off,' can both serve as matrix verbs, they are counted as two morphemes. Also, grammatical morphemes, such as the aspect marker -le and the nominal classifier - $g e$, are counted as one morpheme. Moreover, based on Brown's rules for calculating MLU in English data (1973: 54), I applied some rules when transcribing the Mandarin data to avoid inaccurate counts of MLU. These rules eliminate or specially-mark cases such as stammering, identical consecutive words, interruption, unintelligible words, fillers, songs, and poems.

With respect to verb categorization, lexical aspect is compositional and the aspectual interpretation of a predicate depends on both the verb and its object arguments. Given the short MLU (mean: 2.73) of our children and the pro-drop parameter of Mandarin, it is not uncommon that the arguments are missing. This makes it difficult to define whether a predicate is of the situation type of activity (e.g., run) or accomplishment (e.g., run a mile). However, it is not problematic to identify RVCs because they usually possess two parts, a verb and a result state, such as fang-hao (put-good) 'put in good order.' Therefore, I separated the verbs produced by the children into two main categories: statives and eventives. Then I further divided the eventive verbs into [+resultative] and [-resultative]. The progressive marker zai serves as a test to help differentiate [-resultative] and [+resultative] verbs. For instance, zhao 'look for' can occur with zai in a sentence, as in (36a); thus, it is a [-resultative] verb. The RVC zhao-dao (look for-reach) 'find' cannot appear with $z a i$, as in (36b), because it includes a result state; hence, it is a [+resultative] verb. And a [+resultative] verb can co-occur with the perfective -le without question, as shown in $(36 \mathrm{c})$. 
(36) a. wo zai zhao wo-de qianbao. I ZAI look:for I-GEN wallet 'I am looking for my wallet.'

b. *wo zai zhao-dao wo-de qianbao. I ZAI look:for-reach I-GEN wallet '*I am finding my wallet.'

c. wo zhao-dao-le wo-de qianbao. I look:for-reach-LE I-GEN wallet 'I found my wallet.'

Adjectives function as verbs in Mandarin. Adjectival verbs can take a non-ambiguous perfective -le, as in (37). Although adjectival verbs are stative verbs in Mandarin, they were not discussed in other studies and adjectives are not verbs in English. To better compare the current study with studies of other languages, I counted statives and adjectives separately.

(37) ta shou-le san-bang.

he thin-LE three-pound

'He lost three pounds.'

Furthermore, due to the lack of tense morphology in Mandarin, events of verb-le in this study are divided into 'completed' and 'not-completed' actions according to the context; thus, we may better compare the English data with the Mandarin data when examining the Prototype account.

Finally, in the previous studies regarding Mandarin -le, researchers did not distinguish the two les. Although Erbaugh (1985, 1992) notices the existence of two les but because most -les produced in her data are sentence final (as are ours), she takes them to be ambiguous and counts them as verb-le. Li (1990) simply treats verb-le and sentence final le as one morpheme with the same 
meaning. In the current study, verb-le and sentence le are separated to the extent possible. I will show below that excluding non-ambiguous sentence les is important to assure the distributional bias to be found for the perfective -le.

\subsection{Results}

Table 1 presents the co-occurrence of grammatical and lexical aspect (verb types) of Nana and Didi's data.

Table 1. Co-Occurrence of Grammatical and Lexical Aspect: Nana and Didi Combined

\begin{tabular}{|c|c|c|c|c|c|}
\hline \multirow[t]{2}{*}{ Verb types } & \multirow[t]{2}{*}{ Stative } & \multicolumn{2}{|c|}{$\begin{array}{c}\text { Eventive } \\
\text { (activity, accomplishment, } \\
\text { achievement) }\end{array}$} & \multirow[t]{2}{*}{ Adj. ${ }^{\text {iv }}$} & \multirow[t]{2}{*}{ Total } \\
\hline & & [-Resultative] & [+Resultative] & & \\
\hline Basic form & 299 & 1746 & 753 & & 2798 \\
\hline \begin{tabular}{|l} 
Action \\
completed
\end{tabular} & & 8 & 184 & & 192 \\
\hline$\left.\right|^{-L E} \begin{array}{l}\text { Action not- } \\
\text { completed }\end{array}$ & 1 & 1 & 17 & 45 & 64 \\
\hline$Z A I-$ & 1 & 83 & 4 & & 88 \\
\hline$-Z H E$ & 12 & 9 & & & 21 \\
\hline$-G U O$ & & 4 & & & 4 \\
\hline Reduplicated $^{\mathrm{i}}$ & & 51 & 3 & & 54 \\
\hline$Y O U_{-}^{\mathrm{ii}}$ & 7 & 13 & 11 & & 31 \\
\hline MEIYOU ${ }_{-}^{\mathrm{iii}}$ & 11 & 8 & 13 & 5 & 37 \\
\hline YOUMEIYOU? & & & 1 & 1 & 2 \\
\hline Total & 331 & 1923 & 986 & 51 & 3291 \\
\hline
\end{tabular}

i. The reduplicated form of a verb expresses the delimitative aspect $(\mathrm{Li}$ \& Thompson 1981), which means doing an action a little bit, e.g., kankan 'look look' means 'take a look.' Reduplicated adjectives are 
40 The Aspect Marker -Le in Early Child Mandarin

excluded because they do not provide aspectual reading as other verbs. ii. Wang (1965) and Li \& Thompson (1981) noticed that you- 'have' is a variant of the perfective -le, especially in Southern Mandarin.

iii. Meiyou 'not-have' in negative sentences is the counterpart for both -le and you in affirmative sentences. You-mei-you 'have-not-have' forms the A-not-A (verb or not) questions for both -le and you.

iv. Adjectives in their basic form are not counted in this research because many of them are not clearly a free morpheme. For instance, in early ages, xiaozhu 'small pig' always appears as a fixed item; thus xiao 'small' cannot be counted as a free morpheme.

\subsection{The Distributional Bias}

The data of the current study support the distributional bias found in the English and previous studies as presented in Table 1. The children initially use the perfective -le $(\mathrm{n}=256)$ with [+resultative] verbs $(79 \%)$ and use the imperfective zai $(\mathrm{n}=88)$ with [-resultative] verbs (94\%). If there were no distributional bias, we would expect -le and zai to show up with a variety of verb types. Among the total 986 [+resultative] verbs, only $20 \%$ of them appeared with -le, which suggests that children are not treating [+resultative] verbs plus -le as an idiom or compound.

Focusing on the distribution of the marker -le, Figure 1 presents the use of -le with verb-le and sentence le combined. Figure 2 excludes the non-ambiguous sentence le cases - cases where le is sentence final and is not a verbal suffix, and cases which can be negated by $b u$ 'not' as discussed in section 2.2.2. These two figures argue for a separation between verb-le and sentence le. The reason is that if verb-le and sentence le are counted as the same morpheme, as in previous studies, the distribution of the Mandarin 'perfective marker' will differ more dramatically from other languages. First, recall that Shirai \& Andersen's (1995) subjects produced $94-100 \%$ of their past -ed with achievement verbs. My subjects, however, used $72 \%$ of the verb-le with [+resultative] 
verbs in completed events (Figure 2) and only $46 \%$ of -le (verb-le and sentence le combined) with [+resultative] verbs in completed events (Figure 1). Therefore, if verb-le and sentence le are counted as a group, the percentage of the cases where -le and a [+resultative] verb occur together in completed events will decrease from $72 \%$ to $46 \%$, which differs greatly from the English finding.

Second, 28\% verb-le and sentence le combined (Figure 1) appear with stative verbs, including adjectival verbs. This is very different from the result found in the English data, in which nearly zero percent of the past -ed appears with verbs other than achievement verbs. In order to more accurately compare the perfective marker in Mandarin with its counterpart in other languages, it is necessary to separate the two les. Considering verb-le alone in Figure 2, 18\% of them appear with stative or adjectival verbs. This is smaller than what I found when mixing verb-le and sentence le together (28\%), and is comparatively more consistent with the English data.

Figure 1. Distribution of Verb-Le and Sentence Le Combined

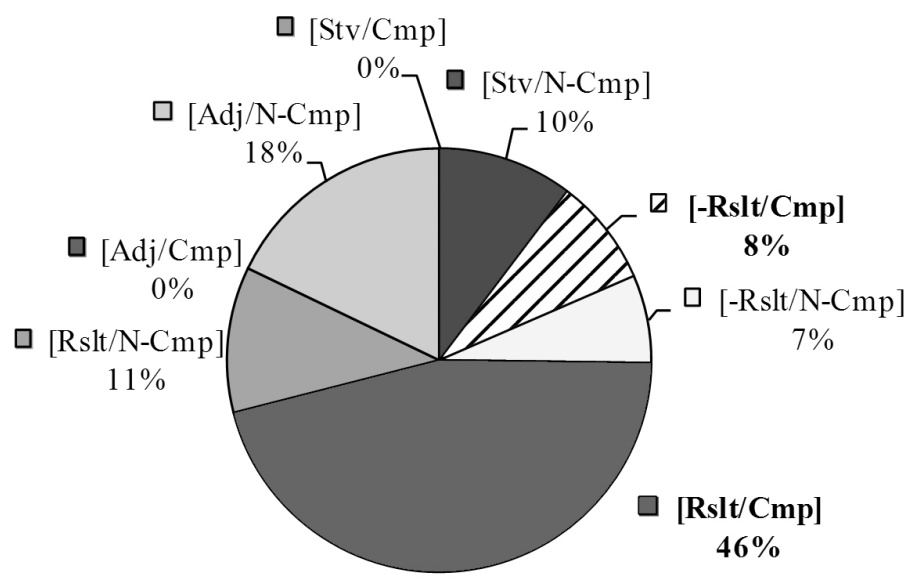


Figure 2. Distribution of Verb-Le

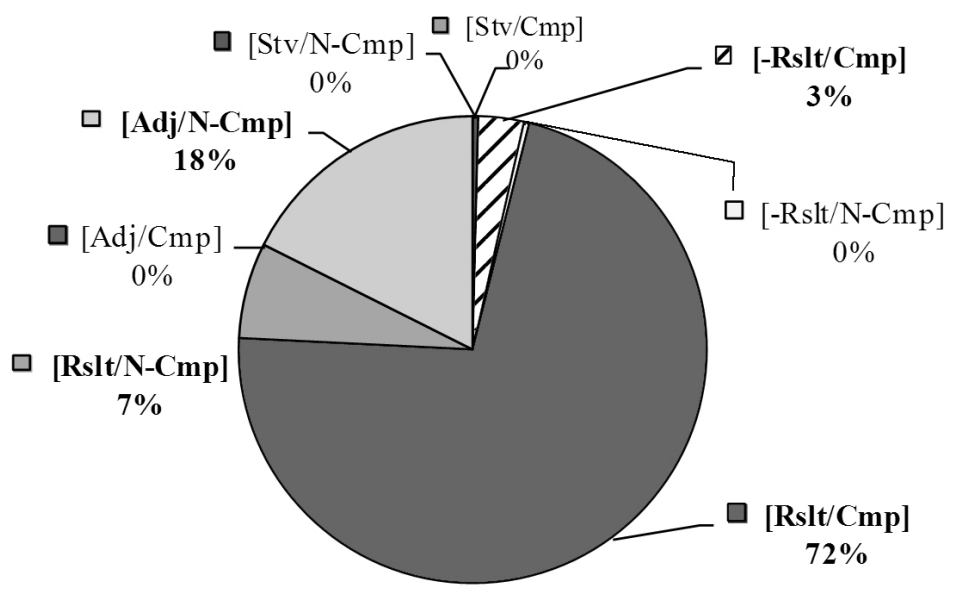

Former studies focus on the distributional bias between the perfective or past marker and achievement verbs. They began their analysis from analyzing the cases with perfective or past marker. But if we look at the data going from achievement verbs (or [+resultative] verbs in this study) and associate them with perfective or past markers, we may discover a very different result, as shown in Figure 3. Nearly $80 \%$ of the [+resultative] verbs associate themselves with various forms (basic, reduplicated, and so on) other than with the perfective-le. 
Figure 3. Distribution of [+Resultative] Verbs in Various Forms

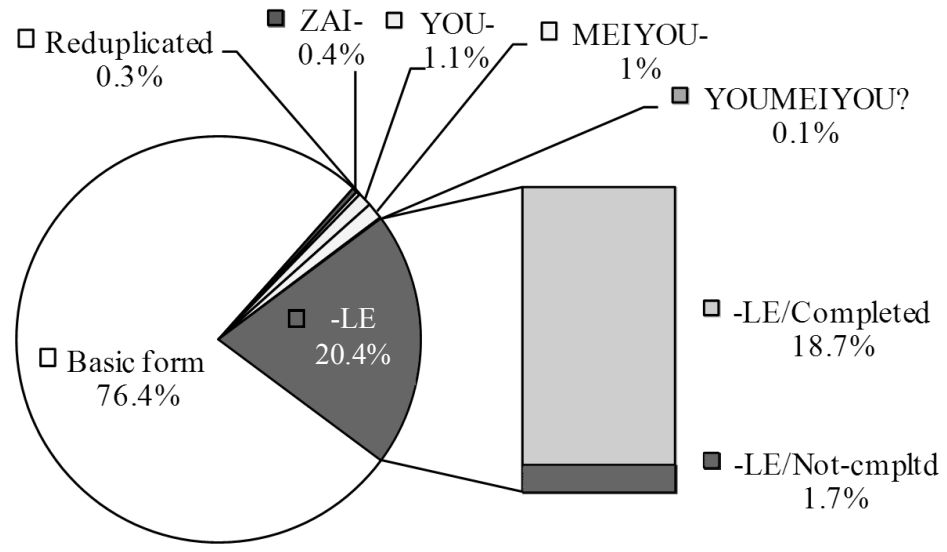

To sum up, my data are consistent with the distributional bias found in other languages: about $79 \%$ perfective -le appear with [+resultative] verbs and 94\% imperfective zai appear with [-resultative] verbs. I also argue that it is crucial to separate perfective-le from sentence final $l e$ in order to have evidence more comparable with data from other languages. Besides, previous studies discuss the distributional bias starting from associating the aspect markers with verbs, but most Mandarin verbs appear in their basic forms without aspectual marking, which should be taken into consideration.

\subsection{Evidence Opposing the Prototype Account}

\subsubsection{Separation between Telic/-Le and Past}

When examining the sentences with -le, I find that children show a separation between telic/-le and past because the [+resultative]-le sequence is found also in not-completed/non-past 
events. In Figure 2, a total of 79\% -le appear with [+resultative] verbs, which is the combination of $72 \%$ completed events and $7 \%$ not-completed events. In Figure 4, the sequence of a [+resultative] verb plus -le is produced in completed events (33-100\%), and in not-completed events (0-25\%) across age. Even in the very early stages, -le is never exclusively used with [+resultative] verbs in completed events as it is by English children.

Figure 4. Interaction between Perfective-Le, Verb Types, and Completedness

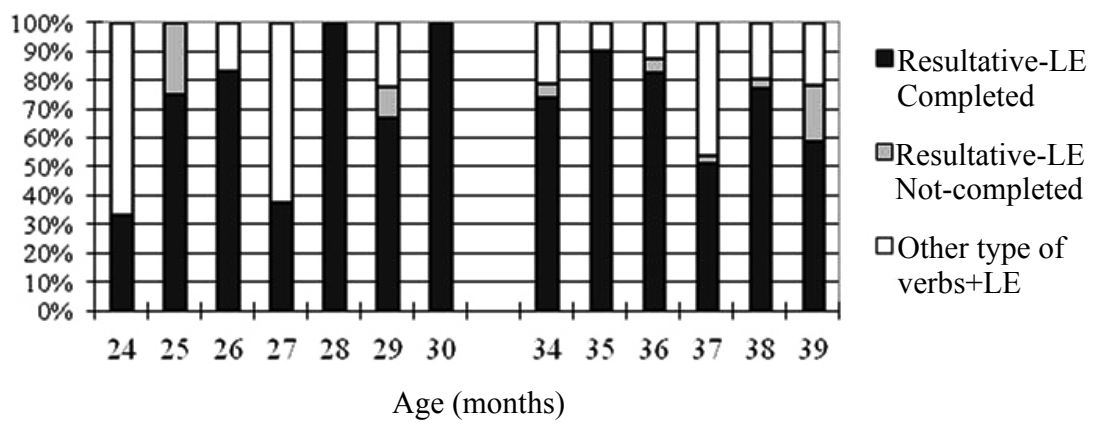

The following examples illustrate how children use the $[+$ resultative $]$ verb + -le sequence in not-completed events.

(38) baba zou-le de shihou, mama jiu ... (Didi 3;3)

Dad leave-LE when, Mom then

'When Dad leaves, then Mom (will) ...'

(39) a. kuaiyao diao-xialai-le. (Didi 3;0) soon fall-down toward the speaker-LE

'. . . is going to fall down soon.' (refers to a toy lion) 
b. shizi meiyou kuaiyao diao-xialai.

lion not-have soon fall-down toward the speaker 'The lion is not going to fall down soon.'

c. *shizi bu kuaiyao diao-xialai le. lion not soon fall-down toward the speaker SFP 'The lion is not going to fall down soon.'

-Le in sentence (38) is not a sentence final particle because it is not in the sentence final position and it is evidently a verb-le. However, as discussed in the section about perfective markers (section 2.2.2), when -le follows a verb and locates in the sentence final position as in (39), it is necessary to identify whether it is purely a verb-le, a sentence final particle, or a combination of the two. One way to differentiate between the two les is that $b u$ 'not' is the morpheme used to negate sentence $l e$, while to negate verb-le, mei(you) 'not(-have)' should be used instead. Sentence (39a) is a sentence without subject. According to the context, I restore the subject, a toy lion, and use meiyou and $b u$ in sentences (39b) and (39c) respectively to test whether -le in (39a) is a verb-le or a sentence final particle. The grammaticality of (39b) and the unacceptability of (39c) make it clear that -le in (39a) is a case of verb-le, not sentence le. Otherwise, sentence (39c) would be grammatical because $b u$ should be able to co-occur with the sentence final le.

Examples (38) and (39) clearly demonstrate that telic verbs (i.e., [+resultative]) and perfective -le can be used in not-completed events. Accordingly, telic/-le should be separated from past.

\subsubsection{Separation between Telicity and $-L e$}

It is not just a matter of saying that children first associate particular types of verbs predominantly with the perfective -le, just like past -ed always appears with telic verbs in early English. 
Rather, how the perfective marker associates with atelic verbs should also be examined. In Figure 2, a total of $21 \%$ verb-le appears with atelic verb, i.e., [-resultative], stative, and adjectival verbs. Figure 5 shows that $-l e$ is used with atelic verbs even in the early stages. In other words, Mandarin-speaking children do not always associate -le with telicity.

Figure 5. Interaction between Perfective-Le and Telicity

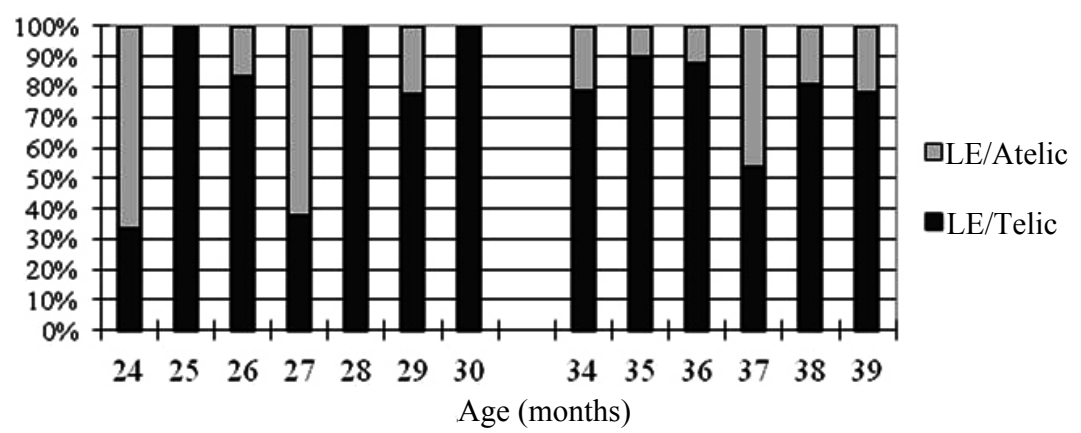

Specific examples to support the separation between telicity and -le can be found below. Children as young as two-year-olds have already used -le with atelic verbs, such as the adjectival verb hao 'good' in (40) and the activity verb $k u$ 'cry' in (41). One may suggest that the predicate type of (40) is a [+resultative] because its translation indicates the emergence of a result. However, sentence (40) is a case of an adjectival verb, and one can interpret (40) as the emergence of a state. As discussed earlier, the perfective marker can work with stative or adjectival verbs to indicate ingressive aspect.

(40) hao-le. (Nana 2;0)

good-LE

'(It) is done.' (responding to 'Is the chicken done?') 


\section{(41) wo ca biti ku-le. (Didi 2;10) \\ I wipe snivel cry-LE \\ 'I cried (when) I have my nose wiped.'}

In short, children seem to be able to recognize perfectivity and telicity as two distinct categories because they do not always combine perfective -le with telic verbs.

\subsubsection{Evidence for Two Les}

In the previous sections, we learned that Mandarin-speaking children do not put past/perfective/telic as a macro-category. They can separate them and use them differently. A further question arises: do children understand there are two les in Mandarin and that the two les should be used differently? Evidence has shown that, syntactically, children use the two les in different positions. I have discussed various examples where -le is used immediately after a verb. Sentences (42) and (43) indicate that le does not always follow a verb. It can be preceded by a pronoun wo 'I; me' in (42) or a common noun gushi 'story' in (43).

(42) jiejie, huan wo le. (Nana 2;2)

old-sister, change me SFP

'Old-sister, it's my turn (now).'

(43) wo yao jiang gushi le. (Nana 2;4)

I want tell story SFP

'I want to tell (a) story (now).'

Notice that these two examples were chosen from the data recorded at age 2;2 and 2;4. If we compare Erbaugh's finding (1992) that children acquire -le before 2;4, then these data suggest that as soon as children produce -le, they use it in different positions, namely, in verbal suffix position and in sentence final 
position following words other than verbs.

More evidence arguing for children's knowledge of the two les is that to make a negation or an A-not-A (verb or not) question for verb-le (but not the sentence final le), you 'have' or meiyou 'not-have' has to be used. The rule is that in order to make a negation or an A-not-A question for -le, one needs to omit -le in the affirmative sentences and mark the sentences with meiyou or you-mei-you, as shown in (44a), (44b), and (44c) respectively.

(44) a. ta chi-le niurou.

he eat-LE beef

'He ate/has eaten beef.'

b. ta meiyou chi niurou.

he have-not eat beef

'He has not eaten/did not eat beef.'

c. ta you-mei-you chi niurou?

he have-not-have eat beef

'Has he eaten/Did he eat beef or not?'

Evidence also indicates that children know the unacceptability of -le co-occurring with meiyou. In (45), if the child had not acquired the rule that -le and meiyou are incompatible within a sentence, we would expect that an error like mei nong-hao-le 'not makegood-LE' would occur, which mistakenly put mei and -le together.

(45) Adult: wo nong-hao-le.

I make-good-LE

'I have made it done.'

Nana $(2 ; 2)$ : ni hai mei nong-hao. you still not make-good 'You've not finished it yet.' 
Possible error: *ni hai mei nong-hao-le. you still not make-good-LE

An example like (46), in which an adult and a child talk about a toy being thrown up to the ceiling, makes it even more apparent that the child as young as two and a half has acquired the rather complicated rule that you serves as the counterpart of verb-le in negation and interrogatives (Wang 1965).

(46)

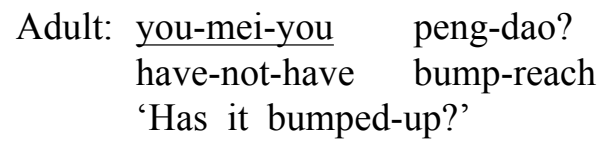

Nana $(2 ; 6)$ : meiyou. not-have 'No.'

Adult: (throw the toy up to the ceiling again)

Nana: you, peng-dao-le. have, bump-reach-LE

'Yes, (it) has bumped up (to the ceiling).'

Furthermore, to negate sentence le, children present their adult-like language competence that the negation marker $b u$ 'not' can be directly added to the sentence without dropping le. Again, from examples (47) and (48), which were produced at a very young age, we can see that as soon as children start to use le, they apply $b u$ 'not' to negate sentence le, but use meiyou 'not-have' and verb-le in negation and affirmative sentences respectively, as previously shown in (45) and (46). These examples with verb-le, sentence le, meiyou, and bu support my proposal that it is not impossible to differentiate verb-le from sentence le in child Mandarin. 
(47) bu jian le. (Nana 2;1)

not see SFP

'(It) disappeared.'

(48) xianzai bu shi le. (Nana 2;6)

now not be SFP

'Now (I'm) not.'

\section{Conclusions}

The Prototype account gives reasons for the distributional bias of aspect in English by arguing that children first use past morphology to mark prototypical past, i.e., verbs that are [+telic], [+punctual], [+result]. Because prototypical perfective looks almost identical to prototypical past, it seems that past tense encodes perfectivity. Also, because the verbs presenting prototypical past happen to be a specific situation type of verbs, i.e., the achievements, it looks like children are marking the inherent aspectual values of the verbs (telicity) when using past morphology. In other words, it seems that English-speaking children use past -ed to mark a macro-category of past/perfective/telic.

The child Mandarin data, both in Li \& Bowerman's experiments (1998) and the current study, support the distributional bias found cross-linguistically: past/perfective morphology appearing with telic verbs and present/progressive with atelic ones. It appears that -le functions similarly to the perfective marker in other child languages.

However, based on the evidence from the natural speech data of young children, I find that Mandarin-speaking children use the sequence of [+resultative] verb +- le both in completed $(72 \%)$ and not completed events $(7 \%)$, which means children can distinguish telicity/-le from past (this supports Wagner's study $(1997,2001)$ that tense is well understood by children as young as age $2 ; 7$ ). 
Thus, Mandarin-speaking children do not mix telic/perfective and past as a macro-category.

Next, if children are not using -le as a grammatical aspect marker, but as a lexical aspect marker to mark the telicity of the verbs, then every time -le appears, a telic verb should also appear. Evidence has indicated that there is also a distinction between telicity and -le in child Mandarin as they use -le with atelic verbs starting from the early stages (total 21\%). Hence, a category presenting the combination of perfective/telic marked by -le does not exist in child Mandarin, either.

In sum, this study does not support the Prototype account. Mandarin-speaking children are not using the perfective -le to mark a macro-category of past/perfective/telic. In fact, the two year-olds seem to know the differences between verb-le (grammatical aspect), sentence le, tense, and verb types (lexical aspect). They already use -le in a very complicated adult-like way.

The distributional bias of aspect markers in child Mandarin not only desires alternative explanation other than the Prototype account, but also casts some doubt on the Prototype explanation for the English facts and suggests that the English facts must be explained in some other way.

\section{References}

Bohnemeyer, J. \& M. Swift. 2004. Event Realization and Default Aspect. Linguistics and Philosophy 27.3, 263-296.

Brown, R. 1973. A First Language: The Early Stages. Cambridge, MA: Harvard University Press.

Cairns, H. 1996. The Acquisition of Language. Austin, TX: Pro-Ed Inc.

Comrie, B. 1976. Aspect: An Introduction to the Study of Verbal Aspect and Related Problems. Cambridge: Cambridge University 
52 The Aspect Marker -Le in Early Child Mandarin

Press.

Dahl, Ö. 1985. Tense and Aspect System. Oxford: Basil Blackwell. Demuth, K. 1996. Collecting Spontaneous Production Data. In D. McDaniel et al. (eds.), Methods for Assessing Children's Syntax 3-22. Cambridge, MA: MIT Press.

Egerod, S. 1994. Aspect in Chinese. In C. Bache et al. (eds.), Tense, Aspect, and Action: Empirical and Theoretical Contributions to Language Typology 279-310. New York: Mouton de Gruyter.

Erbaugh, M. 1985. Personal Involvement and the Development of Language for Time-Aspect. Papers and Reports on Child Language Development 24, 54-61.

. 1992. The Acquisition of Mandarin. In D. Slobin (ed.),

The Crosslinguistic Study of Language Acquisition Volume III 373-455. Hillsdale, NJ: Lawrence Erlbaum Associates.

Klein, W. et al. 2000. Aspect and Assertion in Mandarin Chinese. Natural Language and Linguistic Theory 18, 723-770.

Li, C. \& S. Thompson. 1981. Mandarin Chinese: A Functional Reference Grammar. Los Angeles, CA: University of California Press.

Li, P. 1990. Aspect and Aktionsart in Child Mandarin. Ph.D Dissertation. University of Leiden.

Li, P. \& M. Bowerman. 1998. The Acquisition of Lexical and Grammatical Aspect in Chinese. First Language 18.3, 311350.

Li, P. \& B. MacWhinney. 1996. Cryptotype, Overgeneralization, and Competition: A Connectionist Model of the Learning of English Reversive Prefixes. Connection Science 8, 1-28.

Li, P. \& Y. Shirai. 2000. The Acquisition of Lexical and Grammatical Aspect. New York: Mouton de Gruyter.

Lu, J. 1975. The Grammatical Item 'Le' in Mandarin. Journal of the Chinese Language Teachers Association 10.2, 53-62.

MacWhinney, B. 2000. The CHILDES Project 2000. Mahwah, NJ: Lawrence Erlbaum Associates. 
McCawley, J. 1992. Justifying Part-of-Speech Assignments in Mandarin Chinese. Journal of Chinese Linguistics 20.2, 211-246.

McDaniel, D. et al. (eds.) 1996. Methods for Assessing Children's Syntax. Cambridge, MA: The MIT Press.

Pinker, S. 1984. Language Learnability and Language Development. Cambridge, MA: Harvard University Press.

Rumelhart, D. \& J. McClelland. 1986. On Learning the Past Tenses of English Verbs. In J. McClelland et al. (eds.), Parallel Distributed Processing: Explorations in the Microstructure of Cognition Volume II 216-271. Cambridge, MA: MIT Press. Shirai, Y. \& R. Andersen. 1995. The Acquisition of Tense-Aspect Morphology: A Prototype Account. Language 71, 743-762.

Smith, C. 1997. The Parameter of Aspect. Dordrecht: Kluwer Academic Publishers.

Stromswold, K. 1996. Analyzing Children's Spontaneous Speech.

In D. McDaniel et al. (eds.), Methods for Assessing Children's Syntax 23-54. Cambridge, MA: The MIT Press.

Swift, M. 2000. The Development of Temporal Reference in Inuktitut Child Language. Ph.D Dissertation. University of Texas, Austin.

Sybesma, R. 1999. The Mandarin VP. Dordrecht: Kluwer Academic Publishers.

Wagner, L. 1997. The Development of Aspect. MIT Working Papers in Linguistics 31, 479-489.

. 1998. The Semantics and Acquisition of Time in

Language. Ph.D Dissertation. University of Pennsylvania. 2001. Aspectual Influences on Early Tense

Comprehension. Journal of Child Language 28.3, 661-681.

Wang, W. 1965. Two Aspect Markers in Mandarin. Language $41.3,457-470$.

Weist, R. 2002. The First Language Acquisition of Tense and Aspect: A Review. Language Acquisition and Language Disorders 27, 21-78. 
54 The Aspect Marker -Le in Early Child Mandarin

Yang, S. 1995. The Aspectual System of Chinese. Ph.D Dissertation. University of Victoria. 